\title{
Characteristic infrared frequencies of rotational isomers of alkyl chlorides
}

\author{
J. J. SHIPMAN*, V. L. Folt* and S. KrIMm† \\ (Received 14 May 1962)
}

\begin{abstract}
A study of the infrared spectra of primary, secondary and tertiary alkyl chlorides reveals that the frequency of the so-called $\mathrm{C}-\mathrm{Cl}$ stretching mode is a function of the detailed structure in the vicinity of the $\mathrm{C}-\mathrm{Cl}$ bond. In primary chlorides the frequency region depends on whether a hydrogen atom or a carbon atom is trans to the $\mathrm{Cl}$ atom across the common $\mathrm{C}-\mathrm{C}$ bond. In secondary chlorides it is found that the trans substituents on both $\mathrm{C}-\mathrm{C}$ bonds adjacent to the $\mathrm{C}-\mathrm{Cl}$ bond are important in determining the frequency region, and a similar result is observed for the tertiary chlorides. Frequency ranges for the various rotationally isomeric structures of primary, secondary and tertiary chlorides are given.
\end{abstract}

\section{INTRODUCTION}

THe association of particular chemical groups with infrared absorption bands in limited regions of the spectrum to build up empirical correlations of chemical configurations with absorption frequencies is an old and widely practiced art. The empirical correlations have been and are very valuable aids in the interpretation of the infrared spectra of large molecules. This report is concerned with the determination of the absorption frequencies associated with rotational isomers of primary, secondary and tertiary chlorides. The infrared spectra of selected model compounds of known structures have been examined in an effort to unambiguously associate absorption bands in restricted spectral regions with particular combinations of chemical and geometrical structure. Our ultimate purpose is to improve our interpretations of the spectra of chlorine-containing polymers and related chlorine containing materials.

The early work concerned with the interpretation of infrared and Raman spectra of small alkyl halides and dihalides on the basis of internal rotational isomerism has been covered by Mizushima [1]. Since then, Brown and Sheppard [2-4] have published infrared studies on the rotational isomerism of ethyl, propyl and butyl halides, dihalides and a few higher halides as well. KRIMM and LIANG [5] considered the possibility of rotational isomerism in the assignment of the infrared frequencies of

* The B. F. Goodrich Company, Research Center, Brecksville, Ohio.

$\dagger$ Randall Laboratory of Physics, University of Michigan, Ann Arbor, Michigan.

[1] S. Mrzushrma, Structure of Molecules and Internal Rotation. Academic Press, New York (1954).

[2] J. K. Brown and N. ShepPaRd, Trans. Faraday Soc. 48, 128 (1952).

[3] J. K. Brown and N. ShepPard, Trans. Faraday Soc. 50, 535 (1954).

[4] J. K. Brown and N. Sheppard, Trans. Faraday Soc. 50, 1164 (1954).

[5] S. Krimu and C. Y. Liang, J. Polymer Sci. 22, 95 (1956). 
polyvinyl chloride. KRIMM et al. [6, 7], assigned the $\mathrm{C}-\mathrm{Cl}$ stretching frequencies of highly ordered polyvinyl chloride on the basis of rotational isomerism. Mrzushrma et al. [8] determined the characteristic absorption frequencies for some rotational isomers of primary and secondary halides. The results of these investigations indicate that some of the absorption frequencies associated with the various rotational isomers of chlorine containing organic compounds are, indeed, separable frequencies and that they can be correlated with particular geometrical arrangements in the vicinity of the $\mathrm{C}-\mathrm{Cl}$ bond.

\section{EXPERTMENTAL}

All spectra were obtained using the B. F. Goodrich Infrared Spectrophotometer equipped with a potassium-bromide prism to make the 700-400 wavenumber region accessible. The spectra are those of liquid compounds at room temperature.

Commercial chemicals, without additional purification, were used wherever possible. About half of the compounds were synthesized by known procedures [9]. Inasmuch as the present study concerns bands of medium to strong intensity, extremely high purity samples are not required.

\section{Primary Chlorides}

In normal primary chlorides three isomers attributable to the rotation of the $-\mathrm{CH}_{2} \mathrm{Cl}$ group about an axis colinear with the carbon-carbon bond joining this group to the rest of the molecule are possible. Two are optical isomers and hence spectroscopically indistinguishable. Thus, only two conformations are possible and for which we may expect two absorption bands related to the stretching of the $\mathrm{C}-\mathrm{Cl}$ bond. These conformations for 1-chlorobutane are depicted in Fig. 1. The two spectroscopically different structures may be described by merely specifying whether the chlorine atom is trans to a hydrogen atom or a carbon atom with respect to the carbon-carbon bond. The notation of Mizushrma et al. [8] is convenient for this purpose. According to this system $\mathrm{P}, \mathrm{S}$ and $\mathrm{T}$ specify the chemical type of chloride: primary, secondary and tertiary, respectively. The subscript $H$ specifies that the chlorine atom is trans to a hydrogen atom and the subscript $\mathrm{C}$ specifies the chlorine atom to be trans to a carbon atom.

The spectra of three primary chlorides are shown in Fig. 2. The bands of interest in these spectra are: 648 and $730 \mathrm{~cm}^{-1}$ in (a), 680 and $730 \mathrm{~cm}^{-1}$ in (b) and 653 and $728 \mathrm{~cm}^{-1}$ in (c). The pair of bands in (a) and (c) are characteristic of primary chlorides in which the $-\mathrm{CH}_{2} \mathrm{Cl}$ group is attached to a $\mathrm{CH}_{2}$ group and the pair in (b) are characteristic of primary chlorides in which the $-\mathrm{CH}_{2} \mathrm{Cl}$ group is attached to a carbon atom which is bonded to two other carbon atoms and a hydrogen atom. These characteristic relationships of the observed frequencies with structures are shown to be valid for a number of model compounds in Table 1.

Compound 1, Table 1, ethyl chloride, has only one possible rotational isomer, $\mathrm{P}_{\mathrm{H}}$,

[6] S. Krtmm, A. R. Berens, V. L. Fout and J. J. Shipman, Chem. \& Ind. (London) 1512 (1958).

[7] S. Krimm, A. R. Berens, V. L. Folt and J. J. Shipman, Chem. \& Ind. (London) 433 (1959).

[8] S. Mizushima, T. Shimavouchi, K. Nakamule, M, Hayashi and S. Tsuchiya, J. Chem. Phys. 26, 970 (1957).

[9] E. H. Hontress, Organic Chlorine Compounds. John Wiley, New York (1948). 
and only one band is found in the region of interest at $657 \mathrm{~cm}^{-1}$. Thus, the bands in the 648 to $657 \mathrm{~cm}^{-1}$ region are assigned to the $P_{H}$ conformations of the respective compounds. Similarly, the second compound, neopentyl chloride, can exist only as the $P_{C}$ isomer and only a single band at $723 \mathrm{~cm}^{-1}$ is found. Accordingly, it appears quite reasonable to assign the bands between 723 and $730 \mathrm{~cm}^{-1}$ to the $P_{C}$ conformation for the compounds listed in Table 1. The third compound listed in Table 1, 1-chloro-2-methyl
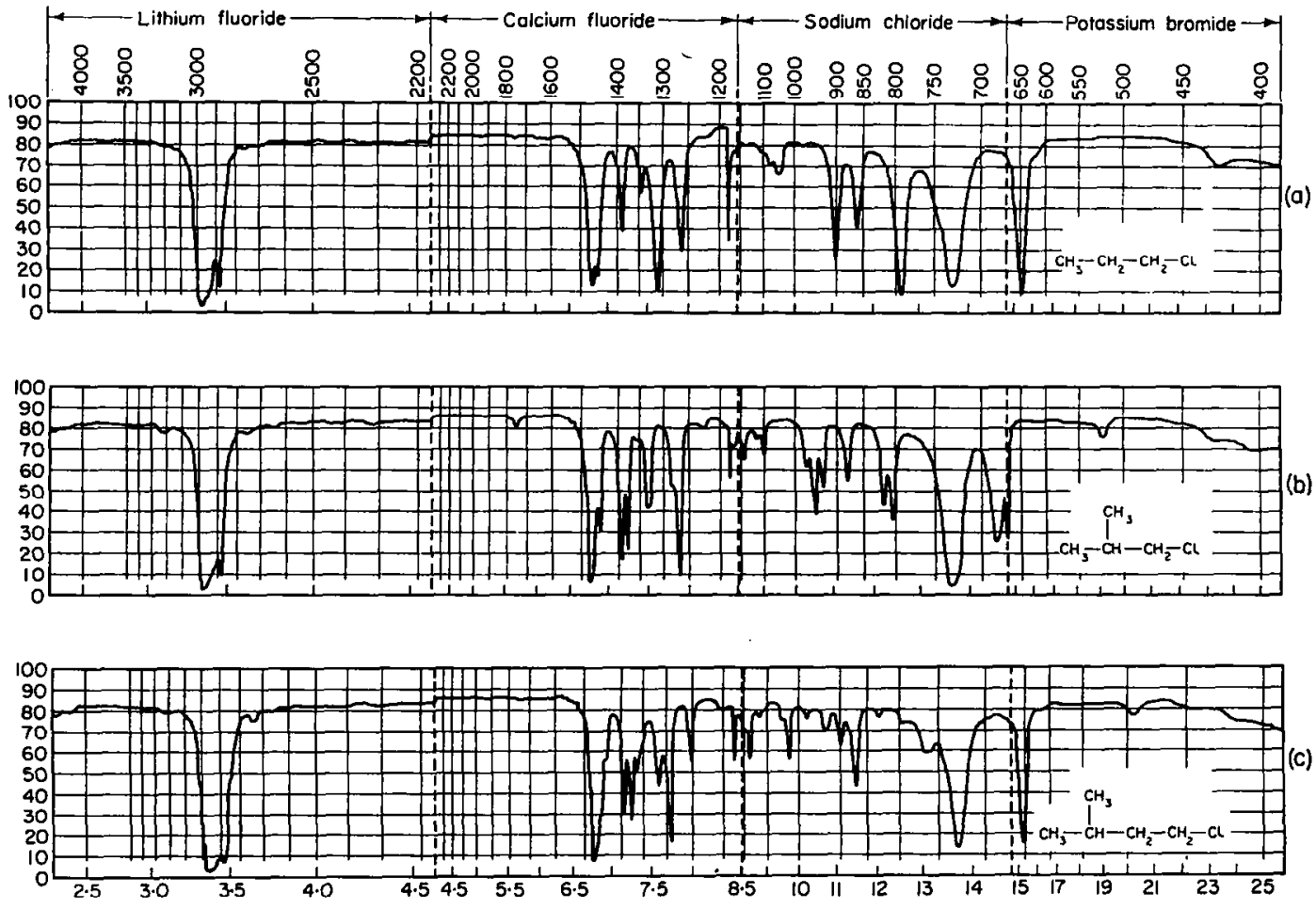

Fig. 2. Infrared spectra of some primary chlorides:

(a) $\mathrm{CH}_{3}-\mathrm{CH}_{2}-\mathrm{CH}_{2}-\mathrm{Cl}$

(c)<smiles>CC(C)CCCl</smiles>

(b)<smiles>CC(C)CCl</smiles>

propane, is of particular interest as it is capable of existing in not only a $\mathrm{P}_{\mathrm{H}}$ conformation but in two optically isomeric $P_{C}$ conformations as well and, consequently, should have two absorption bands, one corresponding to the $\mathrm{P}_{\mathrm{H}}$ conformation and one corresponding to the $\mathrm{P}_{\mathrm{C}}$ conformation. Two bands are observed for this compound. One at $730 \mathrm{~cm}^{-1}$ is apparently attributable to the $P_{C}$ conformation in line with the normal primary chlorides. The second band appears at $686 \mathrm{~cm}^{-1}$ and is very likely 
due to the $\mathrm{P}_{\mathrm{H}}$ conformation. This band is about $35 \mathrm{~cm}^{-1}$ higher in frequency than the $\mathrm{P}_{\mathrm{H}}$ frequencies assigned to normal primary chlorides. The notation $\mathrm{P}_{\mathrm{H}}^{\prime}$ is used to differentiate this band and the structure producing it from the corresponding bands and conformations of the normal primary chlorides. The $\mathrm{P}^{\prime}{ }_{\text {H }}$ conformation of 1-chloro-2-methyl propane is shown in Fig. 1. The notation $\mathrm{P}^{\prime}{ }_{\mathrm{H}}$ denotes that the $\mathrm{CH}_{2} \mathrm{Cl}$ group is attached to a carbon atom to which the other carbon atoms and a hydrogen atom are also attached. This carbon atom will be referred to as a branch site carbon atom. The two other similarly branched primary chlorides listed in Table I also show two bands, one near $680 \mathrm{~cm}^{-1}$ and one near $730 \mathrm{~cm}^{-1}$. The presence

Table 1. Carbon-chlorine stretching frequencies for primary chlorides

\begin{tabular}{|c|c|c|c|c|}
\hline & Structure & $\begin{array}{c}\mathrm{P}_{0} \\
\left(\mathrm{~cm}^{-1}\right)\end{array}$ & $\underset{\left(\mathrm{cm}^{-1}\right)}{\mathrm{P}_{\mathrm{H}}^{\prime}}$ & $\begin{array}{c}\mathrm{P}_{\mathrm{E}} \\
\left(\mathrm{cm}^{-1}\right)\end{array}$ \\
\hline 1. & $\mathrm{CH}_{3}-\mathrm{CH}_{2}-\mathrm{Cl}$ & no band & no band & $657 \mathrm{~s}$ \\
\hline 2. & $\left(\mathrm{CH}_{3}\right)_{3}-\mathrm{C}-\mathrm{CH}_{2}-\mathrm{Cl}$ & $723 \mathrm{~s}$ & no band & no band \\
\hline 3. & $\left(\mathrm{CH}_{3}\right)_{2}-\mathrm{CH}-\mathrm{CH}_{2}-\mathrm{Cl}$ & $730 \mathrm{~s}$ & $686 \mathrm{~s}$ & no band \\
\hline 4. & $\mathrm{CH}_{3}-\left(\mathrm{CH}_{2}\right)_{2}-\mathrm{Cl}$ & $730 \mathrm{~s}$ & no band & $648 \mathrm{~s}$ \\
\hline 5. & $\mathrm{CH}_{3}-\left(\mathrm{CH}_{2}\right)_{3}-\mathrm{Cl}$ & $730 \mathrm{~s}$ & no band & $649 \mathrm{~s}$ \\
\hline 6. & $\mathrm{CH}_{3}-\left(\mathrm{CH}_{2}\right)_{4}-\mathrm{Cl}$ & $729 \mathrm{~s}$ & no band & $651 \mathrm{~s}$ \\
\hline 7. & $\mathrm{CH}_{3}-\left(\mathrm{CH}_{2}\right)_{5}-\mathrm{Cl}$ & $730 \mathrm{~s}$ & no band & $649 \mathrm{~s}$ \\
\hline 8. & $\mathrm{CH}_{3}-\left(\mathrm{CH}_{2}\right)_{6}-\mathrm{Cl}$ & $727 \mathrm{~s}$ & no band & $650 \mathrm{~s}$ \\
\hline 9. & $\mathrm{CH}_{3}\left(\mathrm{CH}_{2}\right)_{15}-\mathrm{Cl}$ & $723 \mathrm{~s}$ & no band & $655 \mathrm{~s}$ \\
\hline 10. & $\mathrm{Cl}-\left(\mathrm{CH}_{2}\right)_{4}-\mathrm{Cl}$ & $731 \mathrm{~s}$ & no band & $648 \mathrm{~s}$ \\
\hline 11. & $\mathrm{Cl}-\left(\mathrm{CH}_{2}\right)_{5}-\mathrm{Cl}$ & $726 \mathrm{~s}$ & no band & $648 \mathrm{~s}$ \\
\hline 12. & $\left(\mathrm{CH}_{3}-\mathrm{CH}_{2}\right)_{2}-\mathrm{CH}-\mathrm{CH}_{2}-\mathrm{Cl}$ & $727 \mathrm{~s}$ & $679 \mathrm{~s}$ & no band \\
\hline 13. & $\mathrm{CH}_{3}-\mathrm{CH}_{2}-\mathrm{CH}-\mathrm{CH}_{2}-\mathrm{Cl}$ & $728 \mathrm{~s}$ & $681 \mathrm{~s}$ & no band \\
\hline 14. & $\left(\mathrm{CH}_{3}\right)_{2}-\mathrm{CH}-\underset{\mathrm{CH}_{3}}{\left(\mathrm{CH}_{2}\right)_{3}-\mathrm{CH}_{3}}-\mathrm{CH}_{2}-\mathrm{Cl}$ & $728 \mathrm{~s}$ & no band & $653 \mathrm{~s}$ \\
\hline 15. & $\mathrm{Cl}-\left(\mathrm{CH}_{2}\right)_{2}-\mathrm{CH}-\left(\mathrm{CH}_{2}\right)_{2}-\mathrm{Cl}$ & $723 \mathrm{~s}$ & no band & $654 \mathrm{~s}$ \\
\hline
\end{tabular}

of a $\mathrm{CH}_{2}$ group between the $\mathrm{CH}_{2} \mathrm{Cl}$ group and the branch site carbon atom (compounds 14 and 15, Table 1) results in a return of the $P_{B}$ band to the $650 \mathrm{~cm}^{-1}$ region, characteristic of normal primary chlorides.

\section{Secondary ChLorides}

With secondary chlorides the situation is somewhat more complex than with the primary chlorides as it is now necessary to consider rotational conformations about two carbon-carbon bonds. In this instance the notations $\mathrm{S}_{\mathrm{HB}}, \mathrm{S}_{\mathrm{CH}}$, and $\mathrm{S}_{\mathrm{CC}}$ are used to specify the particular orientations about the two carbon-carbon bonds on either side of the $\mathrm{C}-\mathrm{Cl}$ bond. The simplest secondary chloride, 2-chloropropane, can exist in only one conformation, $\mathrm{S}_{\mathrm{HH}}$. However, 2-chlorobutane and higher 2-chloro homologs can exist in three rotationally isomeric forms, $\mathrm{S}_{\mathrm{HH}}, \mathrm{S}_{\mathrm{HH}}^{\prime}$ and $\mathrm{S}_{\mathrm{CH}}$ as shown in Fig. 3. In one of the two $\mathrm{S}_{\mathrm{HH}}$ conformations the first four carbon atoms are planar 
while in the other conformation they are non-planar. These conformations are designated as $\mathbf{S}_{\mathrm{HH}}$ (planar) and $\mathbf{S}_{{ }_{\mathrm{HH}}}$ (bent), respectively.

If the chlorine atom is bound to a carbon atom which is located two or more carbon atoms from the end of a hydrocarbon chain, two more conformations, $S_{C C}$ and $\mathbf{S}_{\mathrm{HH}}$, become possible. The $\mathbf{S}_{\text {Hн }}$ conformation is that with a hydrogen atom trans to the chlorine atom on both sides of the $\mathrm{C}-\mathrm{Cl}$ bond; but it also has the nonplanar carbon-atom structure, shown for the $\mathrm{S}_{\mathrm{H}}^{\prime}$ conformation of 2-chloro-butane in Fig. 3, on both sides of the $\mathrm{C}-\mathrm{Cl}$ bond. Although $\mathrm{S}_{\mathrm{CC}}$ and $\mathrm{S}_{\mathrm{HH}}{ }_{\mathrm{H}}$ must be considered in any study of the rotational isomers of secondary chlorides, their concentration at room temperature in liquid samples of compounds which exist in the $S_{\mathrm{CH}}, S_{\mathrm{HH}}$ and $\mathbf{S}_{H \mathrm{H}}^{\prime}$ conformations is expected to be low as scale models of $\mathrm{S}_{\mathrm{CC}}$ and $\mathrm{S}_{\mathrm{HH}}{ }_{\mathrm{H}}$ structures suggest steric interference. We have not yet identified a band attributable to the $\mathrm{S}^{\prime \prime}{ }_{\mathrm{HH}}$ conformation.

The spectra of four selected secondary chlorides are shown in Fig. 4. Each of the three compounds represented in spectra (a), (b), and (c) in Fig. 4 is capable of existing in only one specific conformation. Accordingly, we can now assign, unambiguously, band frequencies for three of the five conformations possible in secondary chlorides. The fourth compound, spectrum (d), Fig, 4, enables us to assign the absorption frequency of a fourth conformation with reasonable confidence.

As noted earlier, 2-chloropropane can exist only in the $\mathrm{S}_{\mathrm{HH}}$ conformation. As is evident from spectrum (a), Fig. 4, only one band in the region of the spectrum under consideration is found for this compound. It appears quite reasonable, therefore, to assign the bands between 608 and $615 \mathrm{~cm}^{-1}$, found for the compounds listed in Table 2 , to the $\mathrm{S}_{\mathrm{HH}}$ conformation.

The compound, 2,2-dimethyl-3-chlorobutane, can exist only in the $\mathrm{S}_{\mathrm{CE}}$ conformation. Nevertheless, as is evident from spectrum (b), Fig, 4, two bands are found in the spectral region of interest, at 730 and $667 \mathrm{~cm}^{-1}$. As all compounds listed in Table 2 capable of existence in the $\mathrm{S}_{\mathrm{CH}}$ conformation show an absorption band between 655 and $672 \mathrm{~cm}^{-1}$, the $667 \mathrm{~cm}^{-1}$ band is assigned to the $S_{\mathrm{CH}}$ conformation. The band at $730 \mathrm{~cm}^{-1}$ is not considered to be associated with any mode which primarily involves the stretching of the $\mathrm{C}-\mathrm{Cl}$ bond.

The compound 3-chloro-2,2,4,4-tetramethyl pentane can exist only in the $\mathrm{S}_{\mathrm{CC}}$ conformation. However, as shown in spectrum (c), Fig. 4, two bands are found in the region of interest, at 758 and $733 \mathrm{~cm}^{-1}$. The more intense band at $758 \mathrm{~cm}^{-1}$ is believed to be due to a vibrational mode of the $S_{C C}$ conformation involving the stretching of the $\mathrm{C}-\mathrm{Cl}$ bond. The origin of the $733 \mathrm{~cm}^{-1}$ band is presently unknown. It is not believed to be related to a mode involving primarily the stretching of the $\mathrm{C}-\mathrm{Cl}$ bond. It may be duc to some vibration of the tertiary butyl group when adjacent to a $\mathrm{CHCl}$ group as a band near this frequency appears in the spectrum of 2,2-dimethyl-3-chlorobutane as noted above. Our assignment of the absorption frequency for $S_{C C}$ is less certain than those for the other secondary chloride conformations. As discussed later, the equilibrium concentation of the $S_{C C}$ conformation at room temperature is not expected to be appreciable in the absence of certain structural and electrical effects which would tend to force the secondary chloride into this conformation. Moreover, the bands for the $\mathrm{S}_{\mathrm{CC}}$ conformations occur in the region of the spectrum where $\mathrm{CH}_{2}$ rocking and other bands are apt to appear, making 
positive identification of $S_{C C}$ bands difficult. Thus, it is not presently possible to present a convincing list of $S_{C C}$ band frequencies for the compounds listed in Table 2 as has been done for the $S_{H H}$ and $S_{C H}$ conformations. Since only one $S_{C C}$ band has identified, the frequency range for bands due to this conformation cannot be estimated from the data in Table 2.
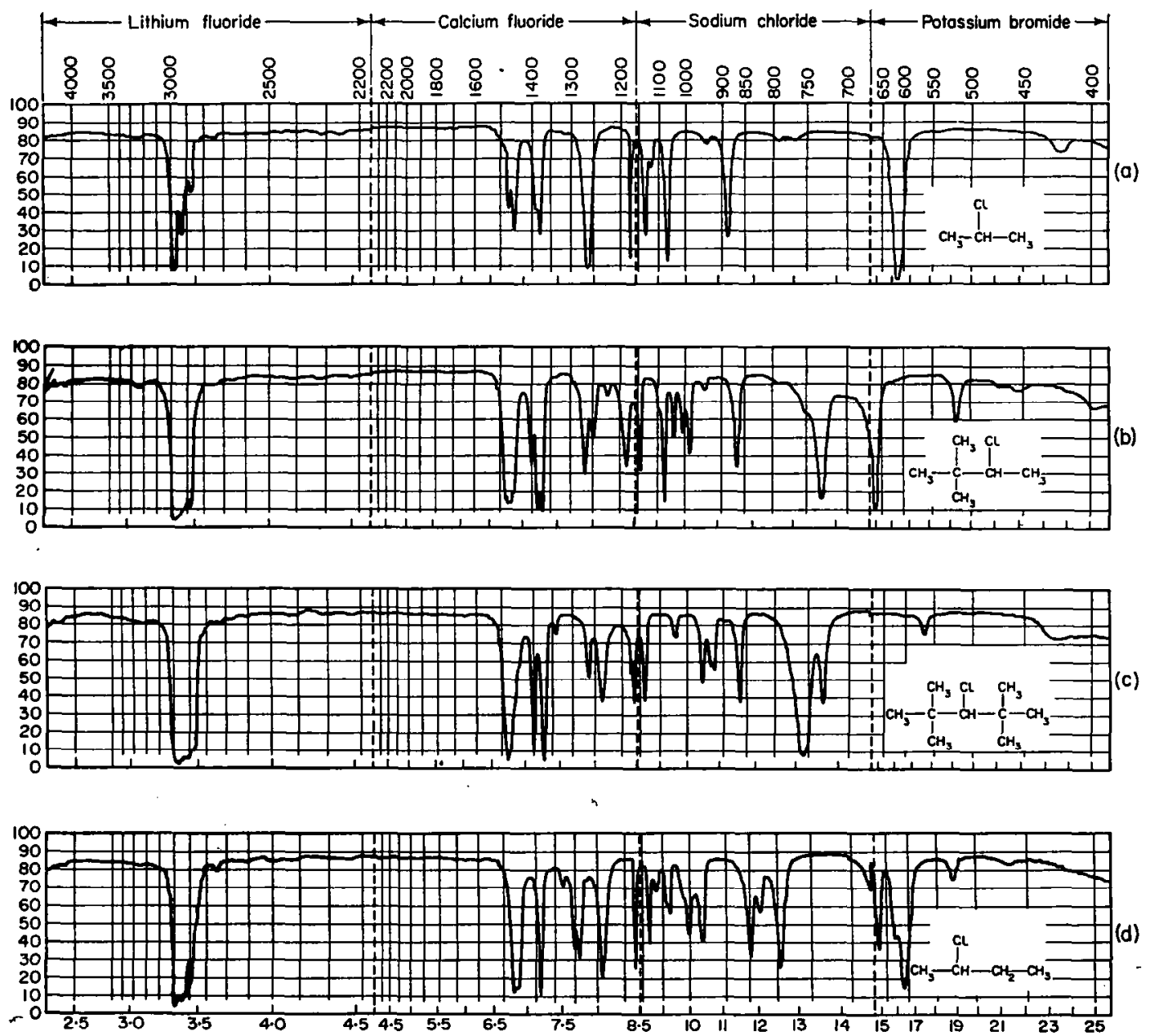

Fig. 4. Infrared spectra of some secondary chlorides:

(a)<smiles>CC(Cl)C(Cl)C(C)(C)C(C)(C)C</smiles>

(b)<smiles>CC(Cl)C(C)(C)Cl</smiles>

(d) $\mathrm{CH}_{3}-\mathrm{CH}-\mathrm{CH}_{2}-\mathrm{CH}_{3}$ 
Table 2. Carbon-chlorine stretching frequencies for secondary chlorides

\begin{tabular}{|c|c|c|c|c|c|}
\hline & Structure & $\begin{array}{c}S_{\mathrm{co}} \\
\left(\mathrm{cm}^{-1}\right)\end{array}$ & $\underset{\left(\mathrm{cm}^{-1}\right)}{\mathrm{S}_{\mathrm{CH}}}$ & $\begin{array}{c}\mathrm{S}_{\mathrm{HH}}^{\prime} \\
\left(\mathrm{cm}^{-1}\right)\end{array}$ & $\begin{array}{c}\mathrm{S}_{\mathrm{HH}} \\
\left(\mathrm{cm}^{-1}\right)\end{array}$ \\
\hline & $\mathrm{Cl}$ & & & & \\
\hline 1. & $\mathrm{CH}_{3}-\mathrm{CH}-\underset{\mathrm{Cl}}{\mathrm{CH}_{3}}$ & & no band & no band & $611 \mathrm{~s}$ \\
\hline 2. & $\left(\mathrm{CH}_{3}\right)_{3}-\mathrm{C}-\underset{\mathrm{Cl}}{\mathrm{Cl}}-\mathrm{CH}_{3}$ & & $667 \mathrm{~s}$ & no band & no band \\
\hline 3. & $\left(\mathrm{CH}_{3}\right)_{3}-\mathrm{Cl}-\mathrm{CH}-\mathrm{C}-\left(\mathrm{CH}_{3}\right)_{3}$ & $758 \mathrm{~s}$ & no band & no band & no band \\
\hline 4. & $\mathrm{CH}_{3}-\underset{\mathrm{Cl}}{\mathrm{CH}}-\mathrm{CH}_{2}-\mathrm{CH}_{3}$ & & $671 \mathrm{~m}$ & $628 \mathrm{~m}$ & $609 \mathrm{~s}$ \\
\hline 5. & $\mathrm{CH}_{3}-\underset{\mathrm{Cl}}{\mathrm{CH}}-\left(\mathrm{CH}_{2}\right)_{2}-\mathrm{CH}_{3}$ & & $670 \mathrm{~m}$ & no band & $612 \mathrm{~s}$ \\
\hline 6. & 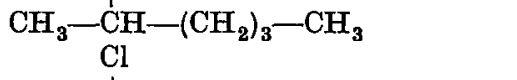 & & $670 \mathrm{~m}$ & no band & $611 \mathrm{~s}$ \\
\hline 7. & 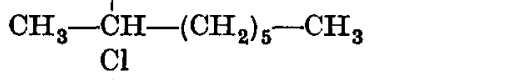 & & $672 \mathrm{~m}$ & no band & $611 \mathrm{~s}$ \\
\hline 8. & $\underset{\mathrm{Cl}}{\mathrm{CH}_{3}-\mathrm{CH}}-\mathrm{CH}_{2}-\underset{\mathrm{Cl}}{\mathrm{CH}}\left(\mathrm{CH}_{3}\right)_{2}$ & & 674 & no band & $615 \mathrm{~s}$ \\
\hline 9. & 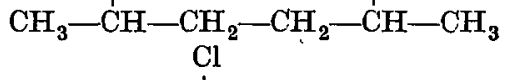 & & $678 \mathrm{~m}$ & $627 \mathrm{sh}$ & $609 \mathrm{~s}$ \\
\hline 10. & $\mathrm{CH}_{3}-\mathrm{CH}_{2}-\underset{\mathrm{Cl}}{\mathrm{CH}}-\mathrm{CH}_{2}-\mathrm{CH}_{3}$ & $749 \mathrm{~m}$ & $667 \mathrm{~m} 655 \mathrm{~m}$ & $628 \mathrm{sh}$ & $609 \mathrm{~s}$ \\
\hline 11. & $\mathrm{CH}_{3}-\mathrm{CH}_{2}-\underset{\mathrm{Cl}}{\mathrm{Cl}}-\left(\mathrm{CH}_{2}\right)_{2}-\mathrm{CH}_{3}$ & $753 \mathrm{~m} *$ & $663 \mathrm{~m}$ & $637 \mathrm{w}$ & $608 \mathrm{~s}$ \\
\hline 12. & $\mathrm{CH}_{3}-\mathrm{CH}_{2}-\underset{\mathrm{Cl}}{\mathrm{CH}}-\left(\mathrm{CH}_{2}\right)_{3}-\mathrm{CH}_{3}$ & $733 \mathrm{~m}^{*}$ & $661 \mathrm{~m}$ & $635 \mathrm{w}$ & $608 \mathrm{~m}$ \\
\hline 13. & $\mathrm{CH}_{3}-\left(\mathrm{CH}_{2}\right)_{2}-\mathrm{CH}-\left(\mathrm{CH}_{2}\right)_{3}-\mathrm{CH}_{3}$ & $733 \mathrm{~m} *$ & $662 \mathrm{~m}$ & $635 \mathrm{w}$ & $610 \mathrm{~m}$ \\
\hline
\end{tabular}

$\mathrm{s}=$ strong $\mathrm{m}=$ medium intense $\mathrm{w}=$ weak $\mathrm{sh}=$ shoulder

* May be confused with $\mathrm{CH}_{2}$ rock

The compound 2-chlorobutane can exist in the $\mathbf{S}_{\mathrm{CH}}, \mathrm{S}_{\mathrm{HH}}$ and $\mathrm{S}_{\mathrm{HH}}$ conformations. Absorption bands are observed for this compound, as shown in spectrum (d), Fig. 4, at 671,628 and $609 \mathrm{~cm}^{-1}$. The 671 and $609 \mathrm{~cm}^{-1}$ bands are assigned to the $S_{\mathrm{CH}}$ and $\mathrm{S}_{\mathrm{HH}}$ conformations, respectively, as discussed earlier. The $628 \mathrm{~cm}^{-1}$ band is accordingly assigned to the $\mathrm{S}_{\mathrm{HH}}^{\prime}$ conformation, the remaining conformation for this compound. As shown in Table 2 two of the 2-chloro homologs and all of the higher 
homologs which can exist in the $\mathrm{S}_{\mathrm{HH}}^{\prime}$ conformation have a band or a shoulder between 627 and $637 \mathrm{~cm}^{-1}$. These bands are reasonably assigned to the $\mathrm{S}_{\mathrm{Hн}}^{\prime}$ conformation. It may be that the lower frequency limit of $\mathbf{S}_{\mathbf{H}}^{\prime}$ bands for the 2-chloro homologs is around $620 \mathrm{~cm}^{-1}$ and that overlapping by the high frequency wing of the more intense $S_{\mathrm{HH}}$ band hides the $S^{\prime}{ }_{\mathrm{HH}}$ band in the spectra of some 2-chloro compounds. This would explain why the $S^{\prime}{ }_{\text {HF }}$ band was not observed for four of the 2-chloro compounds listed in Table 2. This explanation is supported by the fact that the $\mathbf{S}_{\text {HH }}^{\prime}$ bands for the corresponding 2-bromo compounds are easily detectable [10].

As pointed out earlier, 3-chloro and higher chloro compounds are capable, in theory at least, of existing in the $\mathrm{S}_{\mathrm{HH}}$ conformation. Although four of the compounds listed in Table 2 can be considered to be capable of existing in this conformation we have not yet been able to attribute an absorption band to the $S^{\prime \prime}{ }_{\text {HН }}$ conformation. As with the $S_{C C}$ conformation the $\mathbb{S}^{\prime \prime}{ }_{\mathrm{HE}}$ conformation is not expected to exist in appreciable concentration in the absence of structural and electrical effects which tend to force the secondary chloride into this conformation.

\section{Tertiary ChLorides}

Neglecting chain bending and branching, the existence of four rotationally isomeric forms in tertiary chlorides due to rotation about three carbon-carbon bonds, might well be expected on the basis of previous discussion. The four possible forms are $\mathrm{T}_{\mathrm{CCC}}, \mathrm{T}_{\mathrm{CCH}}, \mathrm{T}_{\mathrm{CHH}}$, and $\mathrm{T}_{\mathrm{HHH}}$. Due to steric hindrance effects the occurrence of the $T_{\mathrm{CCC}}$ and $\mathrm{T}_{\mathrm{CCH}}$ forms appears improbable. The two likely conformations, $\mathrm{T}_{\mathrm{CHH}}$ and $\mathrm{T}_{\mathrm{HHH}}$, are depicted in Fig. 5.

The positions of the absorption bands for tertiary chlorides in the spectral region below $800 \mathrm{~cm}^{-1}$ are more widely scattered than for primary and secondary chlorides. Nevertheless, it is still possible to assign the frequency ranges for two of the four conformations, $T_{\mathrm{CH}}$ and $\mathrm{T}_{\mathrm{HHH}}$.

A study of the spectra of the three selected tertiary chlorides shown in Fig. 6 makes it possible to assign, unambiguously, absorption frequencies associated with two of the four possible conformations. Tertiary butyl chloride can exist only in the $\mathrm{T}_{\mathrm{HH}}$ conformation and its spectrum, (a), Fig. 6, has only one band below $800 \mathrm{~cm}^{-1}$. This band at $569 \mathrm{~cm}^{-1}$, therefore, must be due to the $\mathrm{T}_{\mathrm{HHH}}$ conformation. It is evident from the data in Table 3 that the spectra of all the tertiary chlorides which can exist in the $\mathrm{T}_{\mathrm{HH}}$ conformation have bands between 560 and $581 \mathrm{~cm}^{-1}$ which can reasonably be assigned to the $\mathrm{T}_{\mathrm{HHH}}$ conformation. Compound 8 , Table 3 , 3-chloro-3-ethyl pentane, presents an exception to these observations.

The compound 2-chloro-2-methyl butane can exist in two rotationally isomeric forms, $\mathrm{T}_{\mathrm{HHH}}$ and $\mathrm{T}_{\mathrm{CHH}}$. Spectrum (b), Fig, 6, of this compound shows two prominent bands in the region under consideration at 620 and $560 \mathrm{~cm}^{-1}$. The $560 \mathrm{~cm}^{-1}$ band is assigned to $\mathrm{T}_{\mathrm{HH}}$ as discussed above. The $620 \mathrm{~cm}^{-1}$ band, thereforc, must be due to $\mathrm{T}_{\mathrm{CHH}}$, the only other possible conformation of this compound. The data listed in Table 3 indicate that spectra of all compounds which can exist in the $\mathrm{T}_{\mathrm{CHH}}$ conformation have a prominent band in the 611 to $632 \mathrm{~cm}^{-1}$ region which can be assigned to $\mathrm{T}_{\mathrm{CHH}}$. 3-chloro-3-ethyl pentane is again an exception to these observations.

[10] J. J. ShIPMan, V. L. Folt and S. KrIMM. Unpublished work. 

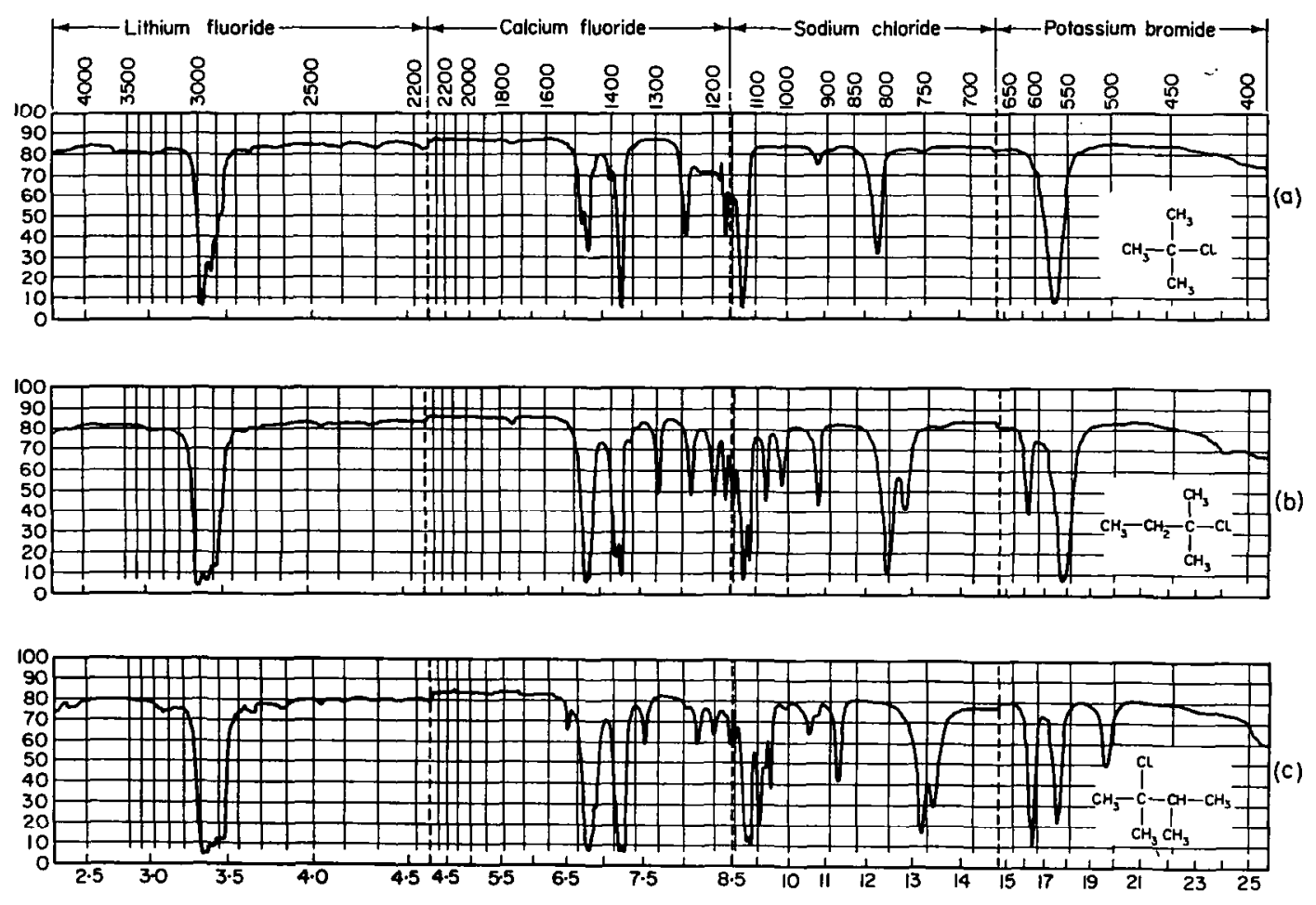

Fig. 6. Infrared spectra of some tertiary chlorides:

(a)<smiles>CC(C)(C)Cl</smiles>

(c)<smiles>CC(C)C(C)(C)Cl</smiles>

(b)<smiles>CCC(C)(C)Cl</smiles>

The frequency ranges for the bands associated with the two conformations of tertiary chlorides, $\mathrm{T}_{\mathrm{CHH}}$ and $\mathrm{T}_{\mathrm{HH}}$ are somewhat wider than those established earlier for primary and secondary chlorides. Although they may be less definitive in some instances, i.e. molecules which behave like 3-chloro-3-ethyl pentane, they are still considered to be quite useful.

As is evident in Table 3 and spectrum (c), Fig. 6, prominent bands appear in the spectra of tertiary chlorides between 500 and $550 \mathrm{~cm}^{-1}$ and also between 700 and $750 \mathrm{~cm}^{-1}$. These bands may be related in some way to the other geometrical conformations of tertiary chlorides but we have not yet been able to assign any of them to any particular structure.

\section{Conclusions}

Infrared absorption data on model compounds show that the frequencies of vibrational modes involving the stretching of the $\mathrm{C}-\mathrm{Cl}$ bond are not only dependent 
Table 3. Carbon-chlorine stretching frequencies for some tertiary chlorides

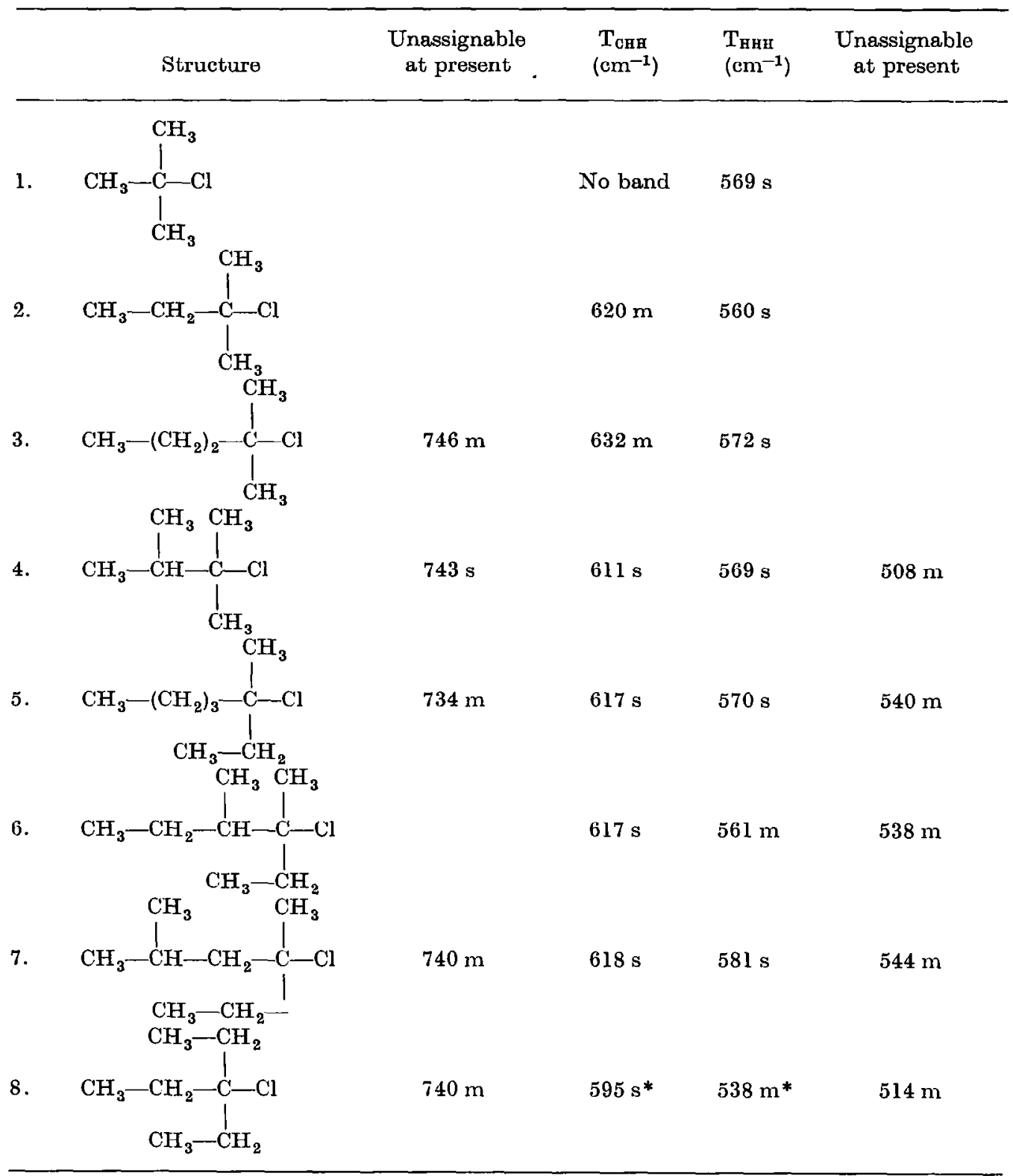

$\mathrm{s}=$ strong $\mathrm{m}=$ medium intensity $*$ = tentative assignment

upon the chemical environment, i.e. whether the chloride is primary, secondary or tertiary, but upon the geometrical conformation of each chemical species as well. The data also show that useful and separable absorption frequencies can be associated with most of the chemical-geometrical structural combinations existing in the immediate vicinity if the $\mathrm{C}-\mathrm{Cl}$ bond. The established correlations of absorption 
frequency with structure for saturated aliphatic monochlorohydrocarbons are summarized in Table 4.

Table 4. Characteristic absorption frequencies for aliphatic saturated monochlorohydrocarbons

\begin{tabular}{lc}
\hline $\begin{array}{c}\text { Chemical-geometrical } \\
\text { combination }\end{array}$ & $\begin{array}{c}\text { Frequency range } \\
\left(\mathbf{c m}^{-1}\right)\end{array}$ \\
\hline $\mathrm{P}_{\mathrm{H}}$ & $648-657$ \\
$\mathrm{P}_{\mathrm{H}}^{\prime}$ (branched) & $679-686$ \\
$\mathrm{P}_{\mathrm{C}}$ & $723-730$ \\
$\mathrm{~S}_{\mathrm{HH}}$ & $608-615$ \\
$\mathrm{~S}_{\mathrm{HH}}^{\prime}$ (bent) & $627-637$ \\
$\mathrm{~S}_{\mathrm{CH}}$ & $655-674$ \\
$\mathrm{~S}_{\mathrm{CC}}$ & 758 \\
$\mathrm{~T}_{\mathrm{HHH}}$ & $560-581$ \\
$\mathrm{~T}_{\mathrm{CH}}$ & $611-632$ \\
\hline
\end{tabular}

The extreme sensitivity of the absorption frequencies of the so-called carbonchlorine stretching bands to the chemical and geometrical environment of the $\mathrm{C}-\mathrm{Cl}$ bond signifies that a separable frequency due solely to the stretching of such a bond does not exist in the usual sense. It is clearly evident that the observed absorption bands are due to complex vibrational modes of which the stretching of the $\mathrm{C}-\mathrm{Cl}$ bond is only a part, and that the relative nuclear motions of these modes differ considerably from one rotational isomer to another. This sensitivity of frequency to structure for bands related to the stretching of a particular bond is unusual among empirical correlations and is very likely due to the large mass of the chlorine atom relative to the masses of the neighboring carbon atoms. It is interesting to note that we have observed even greater frequency differences between the rotational isomers of the corresponding bromides and iodides.

The frequency-structure correlations presented in Table 4 allow unequivocable determinations of chemical type as well as the geometrical orientation of $\mathrm{C}-\mathrm{C}$ bonds in the vicinity of the $\mathrm{C}-\mathrm{Cl}$ bond in many unknown chlorine containing molecules.

In the work reported here the relative concentrations of the various rotationally isomeric conformations are considered to be determined by thermal equilibrium. In other systems, especially high polymers, additional restrictions due to chain entanglements, crystallinity and other factors may be imposed and result in higher concentrations of certain conformations which are considered to be unlikely for these specific model compounds.

Acknowledgements-The authors gratefully acknowledge the efforts of Dr. CharLes ZiegLer, Dr. R. J. FAwCETT and Dr. David Craig in the synthesis of certain of the model compounds. 

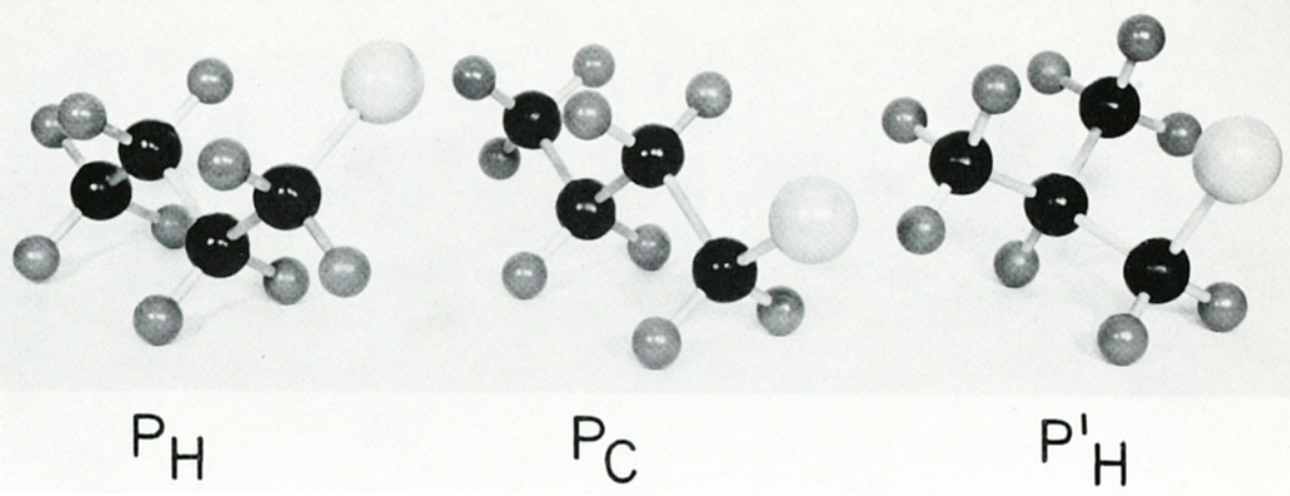

Fig. 1. $P_{t}, P_{C}$ and $P_{H}^{\prime}$ conformations of primary chlorides.

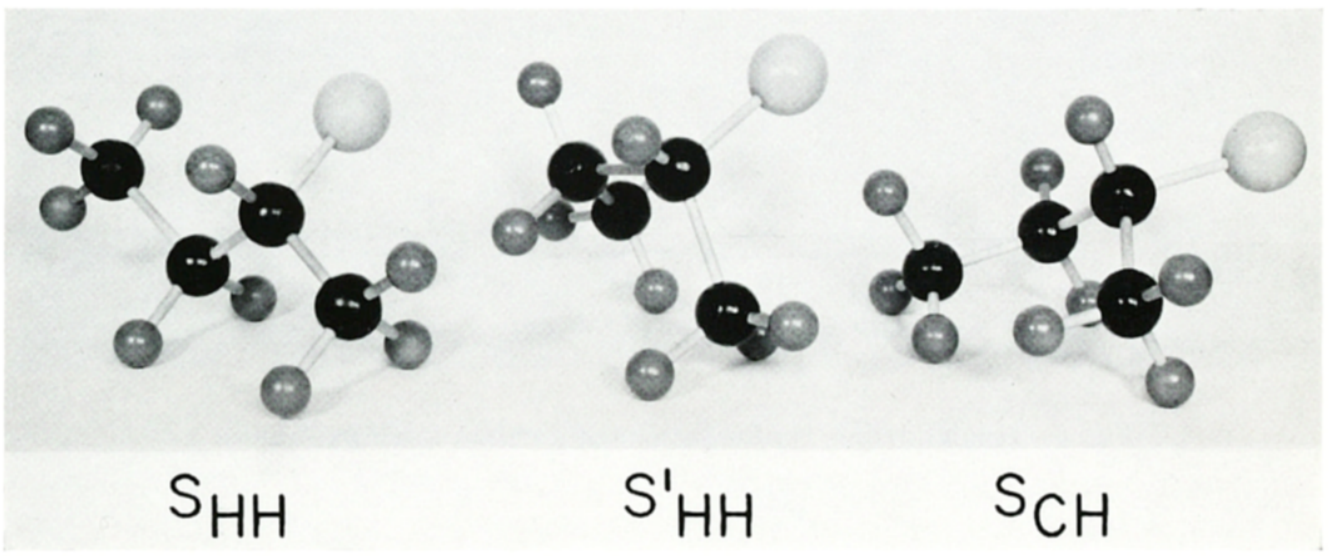

Fig. 3. $S_{\mathrm{HH}}, \mathrm{S}_{\mathrm{HH}}^{\prime}$ and $\mathrm{S}_{\mathrm{OH}}$ conformations of 2-chlorobutane 